\title{
Construir el aire. Arquitectura y diseño hinchable, 1960-1975
}

\author{
Centre Pompidou Málaga
}

Del 8 de noviembre de 2018 al 10 de febrero de 2019

Tras los experimentos llevados a cabo durante la II Guerra Mundial aparecieron unos materiales que permitieron proponer nuevas formas arquitectónicas a partir, sobre todo, de la década de 1960. Una vez reconstruidas la mayor parte de las ciudades europeas, una nueva generación utilizó la arquitectura como refugio y altavoz de sus ideas: una respuesta libre a los proyectos de un racionalismo convertido en movimiento dominante dentro del movimiento moderno.

Las estructuras inflables se convirtieron en las burbujas que contenían las reivindicaciones de unos jóvenes que querían mirar el mundo desde otra perspectiva y (re) pensar la realidad desde la efervescencia de lo alternativo, lo diferente, lo transformador. Los sueños se habían hecho hinchables.

En 1968 se inauguró en París una exposición del colectivo Utopie en la que se reunieron diferentes propuestas construidas con plástico y aire que tuvo una rápida respuesta en diversas publicaciones especializadas, entusiasmadas con las posibilidades formales y conceptuales de los nuevos materiales. Al mismo tiempo que se estaban generando estos proyectos arquitectónicos se comenzaba a ocupar el espacio doméstico: la esfera privada también podía ser inflable. El futuro estaba en el aire: asientos, lámparas o colchones -como el sillón Croissant de 1965- se instalaban en los hogares más vanguardistas. Pero no solo los objetos empezaban a ser hinchables. Otros creadores decidieron asaltar el espacio urbano: la esfera pública aún podía soñar.

Arquitectos como Hans Hollein decidieron habitar oficinas transparentes en mitad de la naturaleza. Se empezaba a hablar de arquitectura biomimética, inspirada en las formas orgánicas y fabricada con materiales artificiales. El resultado eran unos proyectos con menos peso y más efectos, efectos espaciales -y especiales- producidos por la tecnología e incluso las drogas psicotrópicas. El pasado pesado de la construcción -la piedra o la madera, el vidrio o el hierro- despegaba ahora propulsado por los soplos de la imaginación. La fantasía se convertía así en un sinónimo de libertad. Bajo estas propuestas subyacía la idea de una arquitectura resultado de la expansión de la esfera física y psíquica de un ser humano que creaba su propia atmósfe-

1. Instant city, Archigram, 1969. M+ Museum, Hong Kong.

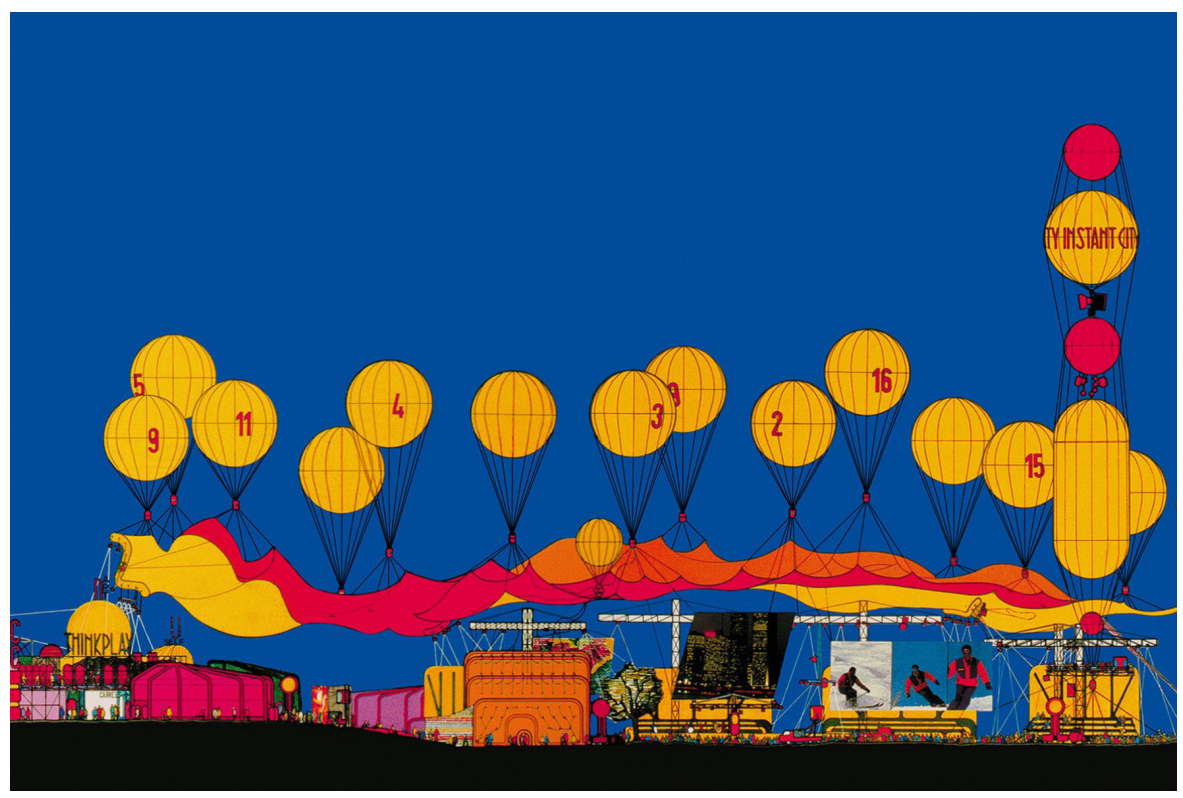




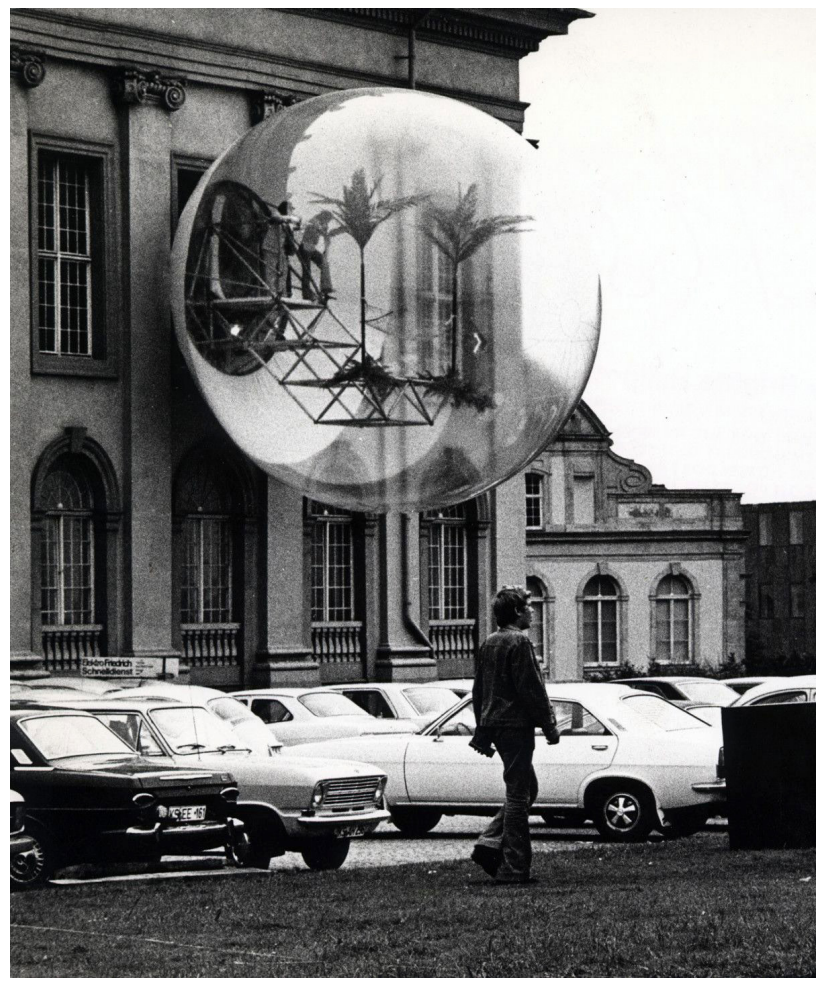

2. Oase no.7, Haus-Rucker-Co, Kassel 1972. Musée national d'Art moderne-Centre Pompidou ra, que simulaba su propio ecosistema, que inventaba un nuevo mundo a su medida.

La Exposición Universal de Osaka de 1970 permitió globalizar este concepto. En este escaparate internacional fueron numerosos los pabellones construidos con plástico y aire generando impresionantes hábitats inflables. Sin embargo, la mayor parte de los proyectos se preocupó más por la espectacularidad formal del resultado que por lo reivindicativo de construir y pensar de una forma nueva. Los sueños se habían empezado a deshinchar y las burbujas estaban cada vez más vacías de subversión. Así, bastaba simplemente con soplar para hacer desaparecer las pompas de la revolución.

Una nueva corriente de pensamiento preocupada por el cambio climático y el agujero de la capa de ozono, la crisis petrolera de principios de la década de 1970 o la generación de una cada vez más sólida conciencia ecológica acabaron desinflando las agitadas cápsulas de la revuelta. El avance tecnológico controló a través de la informática la gestión de las nuevas construcciones y el desarrollo de nuevos materiales acabó con el plástico. Quizás el aire había sido el material de los sueños pero estos quedaron encapsulados en burbujas y efectos espaciales. La utopía había flotado en un mundo ideal pero no consiguió ser tangible.

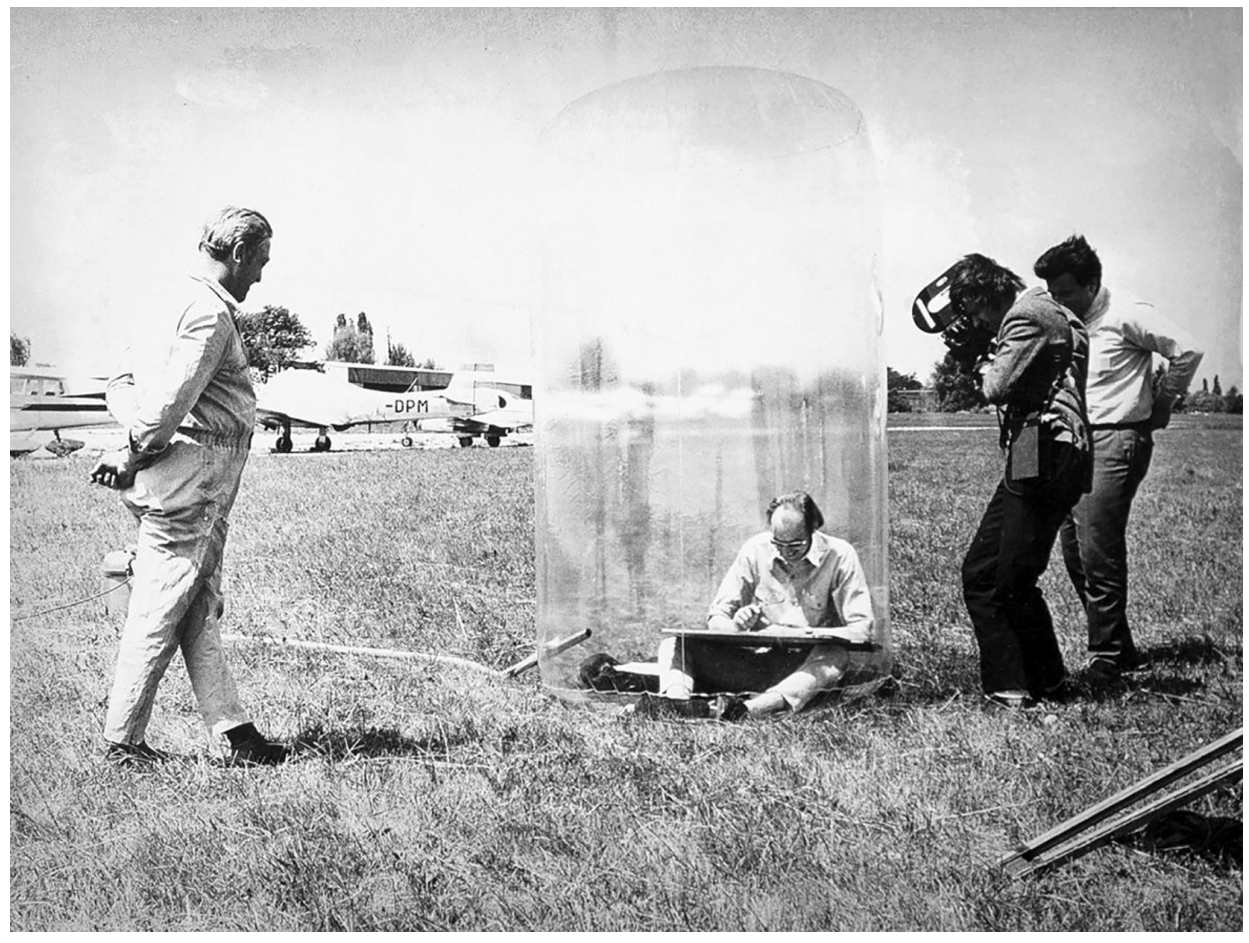

3. Hans Holleins Dans en su oficina móvil, Hans Hollein, 1969. Musée national d'Art moderneCentre Pompidou 


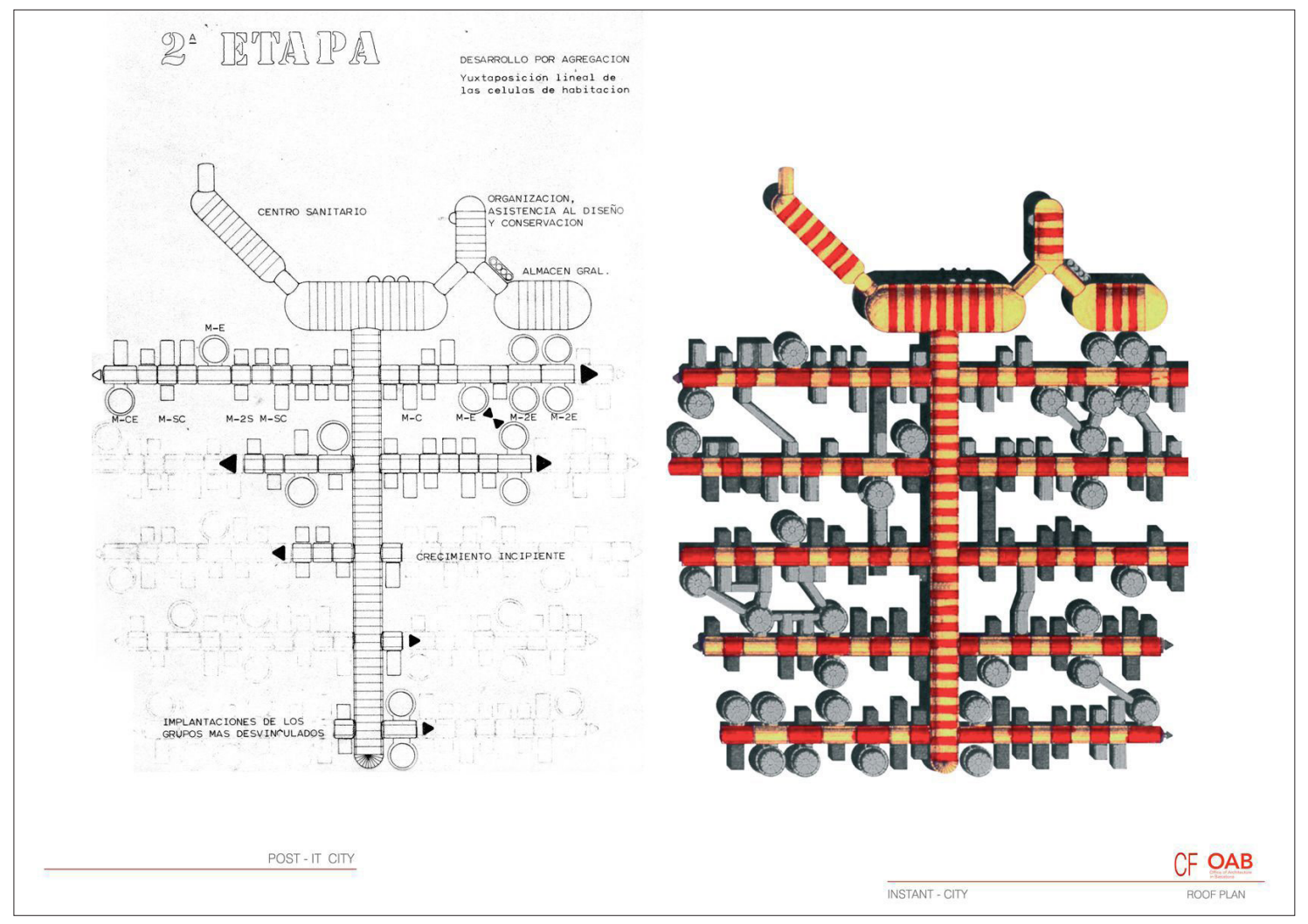

4. Instant city, Carlos Ferrater, Fernando Bendito y José M. Prada Poole, 1970-1971. Fotografía de José Manuel Ferrater-OAB

La exposición se encuentra dividida en seis salas temáticas, con un primer espacio dedicado a Imaginar la ciudad. La reconstrucción de los núcleos urbanos arrasados durante la II Guerra Mundial se había hecho desde la practicidad funcional y económica de unos proyectos que habían tratado de dar una solución rápida a las carencias de una población asolada. En la década de 1960 los jóvenes comenzaron a repensar este modelo, proyectando la arquitectura como una burbuja, un hábitat capaz de desplazarse, flotar, volar y dar respuesta a las demandadas de una sociedad en transformación, volátil como el material con el que estaban construidos los sueños: el aire.

Uno de los proyectos más interesantes de la sala es Control and Choice -1967- del colectivo Archigram. Responde a lo que se puede llamar «megaestructuras», inmensos organismos en los que se diluye la línea entre arquitectura y ciudad. Un nuevo hábitat concebido como un gran monstruo moderno en el que imaginar una vida alternativa a la que ocurría en el exterior. Así, aparecen reunidos conceptos como red, circulación e intercambio en una quimera gigante del flujo y lo efímero. Un mundo imaginario e imaginado lejos de la lógica racional arquitectónica en el que se respira la ilusión de libertad. La defensa del proyecto de arquitectura como una posible utopía moderna manifiesta la voluntad de reforma de la organización de la sociedad y el cambio de uso y comportamiento de un sector cada vez más amplio de la población que reaccionaba ante lo impuesto. Esta fórmula para diseñar nuevas formas de vida se sustentaba en una enorme paradoja: su punto de partida era lo orgánico mientras su materialización era artificial.

El espacio concebido para imaginar la ciudad se concreta con una nueva área temática que se articula bajo el nombre de Construir con el aire. Aquí se exponen proyectos subversivos que, además de plantear esferas habitables alternativas o imaginar otros modelos de ciudad, utilizan el aire como material. Estas propuestas son consecuencia del desarrollo de plásticos más resistentes que se configuraron como una alternativa a los pesados materiales utilizados en 


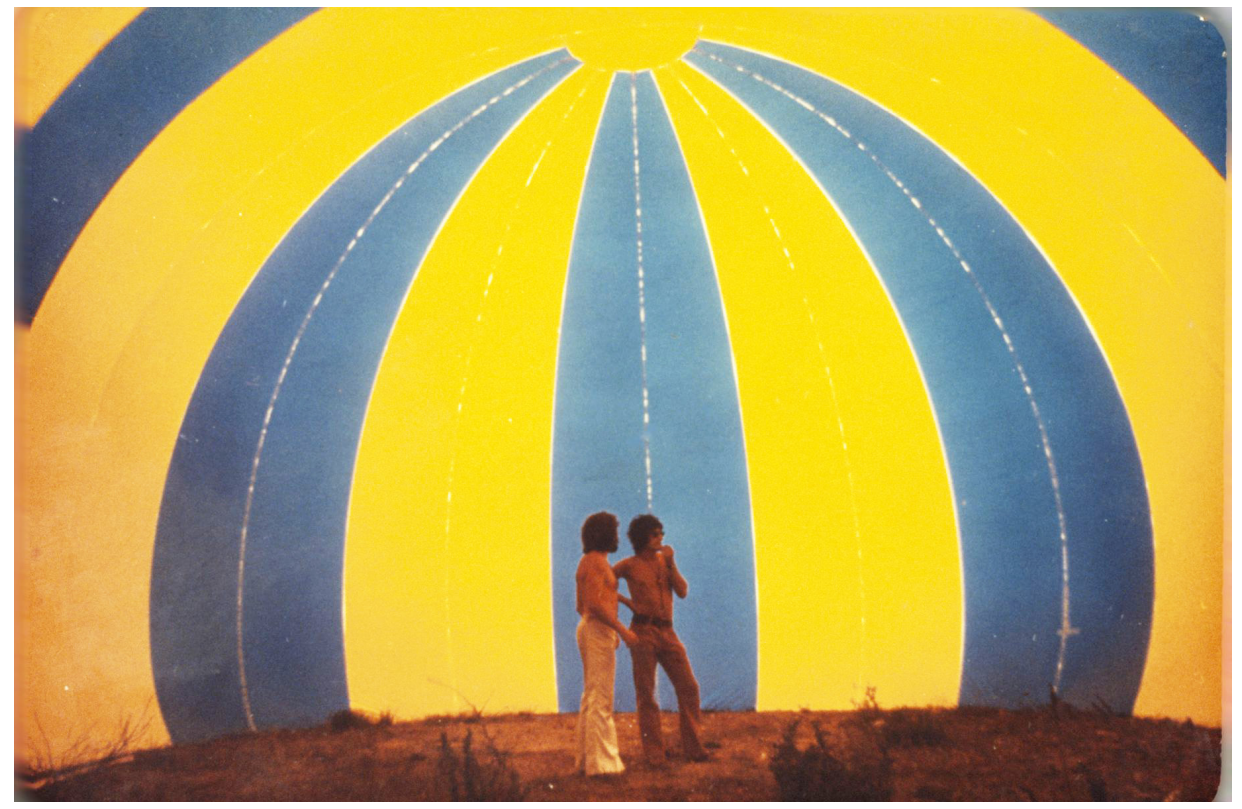

5. Interior de Instant city, Carlos Ferrater, Fernando Bendito y José M. Prada Poole, 1970-1971. Fotografía de José Manuel Ferrater- $O A B$

la arquitectura con la que se reconstruyó Europa tras la guerra. La arquitectura se convierte así en un campo de batalla en el que las normas se subvierten y lo hinchable es sinónimo de libertad. Las nuevas posibilidades permitían unos diseños más libres, menos sujetos a las normas de la gravedad y el equilibrio, tan solo sustentados en la diferencia de presión entre la estructura y el exterior. La arquitectura modulable, ligera y efímera era ahora una realidad: los sueños se habían hecho hinchables.

Arquitectos como Jean Aubert formaron parte de colectivos muy activos en este periodo como el grupo A.J.S. Aérolande, que nació con la intención de plasmar las utopías políticas de sus integrantes a través de los materiales del futuro: el plástico y el aire. Por eso, sus diseños se encuentran también en el siguiente eje temático de la exposición: Vivir en hinchables. La esfera privada será ahora inflable y la vida moderna descansará en asientos de PVC iluminada por lámparas transparentes. Porque no solo los edificios se construyeron con aire, también el mobiliario se expandió por el espacio ocupándolo con sus reivindicaciones. Sin ángulos rectos, apilables y modulares, los diseños de Aérolande explotaron el potencial de los nuevos materiales bajo la estética del pop art, la ciencia ficción y los efectos espaciales.
Probablemente constituyan uno de los colectivos más conocidos internacionalmente y apoyados desde las administraciones públicas, especialmente las parisinas.

Las ideas contenidas en estas burbujas artificiales con formas de mueble revolucionaron los que hasta entonces habían sido los principios del diseño: permanencia, inversión y durabilidad. Los objetos eran ahora producidos en serie, baratos, fáciles de transportar, consumibles, lúdicos, ligeros y transparentes. Comenzaba así la idea de lo desechable, la utilidad de lo efímero. La moda dictaminará lo que sobrevivirá y lo que será cambiado en un instante. El mundo se transforma y autofagocita cada día y lo inflable permite reinventar los espacios al mismo ritmo. El nuevo hábitat humano está hecho de plástico y sus sueños son hinchables.

El desarrollo del ocio y la facilidad de producir objetos inflables en diferentes colores y acabados configura lo que la historiografía del arte ha venido a llamar la estética del relax. El mobiliario es ahora orgánico en sus formas y artificial en sus materiales, efímero como una pompa que puede explotar en cualquier momento. A este concepto se une la idea de cápsula espacial, configurando los escenarios más modernos como una nave nodriza recién aterrizada en la convencional realidad impuesta por la generación anterior. 
En este universo que contiene el aire en vibrantes colores y cómodas formas redondeadas, el trabajo de los arquitectos Jonathan De Pas, Donato D'Urbino y Paolo Lomazzo constituye uno de los ejemplos más destacados. El futuro estaba en el aire. Blow -1967- fue uno de los primeros sillones hinchables producidos en serie, la imagen de una generación efervescente.

Pero no solo la esfera privada será intervenida con plástico, el espacio público también podía ser hinchable. La quinta área temática está dedicada a Intervenir en el espacio público. Aquí los arquitectos jóvenes se relacionarán con artistas, filósofos o sociólogos convencidos de que aquellos lugares que pertenecen a todos son el escenario perfecto para hacerse oír. El cuestionamiento de lo institucional y lo establecido se hará de forma colectiva y la arquitectura se utilizará como herramienta crítica. Comienzan así una gran cantidad de experimentos alrededor de la relación del ser humano con su ambiente. Protegidos por membranas de plástico, ahora es posible habitar la naturaleza. Como una especie de astronauta aislado del exterior para poder sobrevivir, los arquitectos configurarán nuevas burbujas en las que establecerse. Ya no se trata de construir edificios, sino de poner en evidencia el potencial estético-político de la arquitectura a través de la idea de la intervención. Estas propuestas se montan fácilmente y además suponen una nueva experiencia de relación con el entorno. Son casi ciudades invisibles habitadas por unos pocos visionarios, construidas con el espíritu reaccionario de la generación de las revueltas.
En un contexto global en el que las ideas fluían dentro del aire contenido en la arquitectura hinchable, también encontramos algunos ejemplos construidos en España. El más importante de todos se instaló en Ibiza en 1971, entonces una isla en la que se respiraba libertad dentro de un país ahogado por la dictadura. Una vía de escape con unos pocos ecos en la península como Torremolinos o Benidorm. Una utopía. Allí se celebró el VII Congreso del Consejo Internacional de Asociaciones de Diseño Industrial que tuvo lugar en un entorno poco urbanizado. Dos estudiantes de arquitectura, Fernando Bendito y Carlos Ferrater, difundieron en los círculos especializados del panorama internacional el Manifiesto Instant City. El texto hacía un Ilamamiento para crear una ciudad autoconstruida, un gran happening, una performance colectiva que generaría una ciudad efímera. Una forma de hacer la utopía tangible.

José Miguel Prada Poole les ayudó a construir sus sueños con el material más barato de todos: el aire. Se inflaron así un conjunto de módulos de plástico conectados por corredores que se utilizaron de punto de encuentro para los participantes del congreso. La estructura sirvió para generar sinergias entre diferentes disciplinas y supuso una experiencia de socialización en un entorno hinchable. Prada Poole llegó a declarar que «la utopía es posible», puesto que este proyecto catapultó la imagen de la arquitectura española del momento. La ciudad del instante permitió por un momento imaginar un país más libre.

Luis Delgado Mata Universidad de Málaga 